\title{
Intraabdominal vibrator due to a vaginal cuff dehiscence
}

\section{Eric F. Reichman}

Emergency Department, University of Texas Health Science Center at Houston-Medical School, Missouri City, TX, USA

A 31-year-old female presented with severe abdominal pain three hours after vaginal intercourse. This was her first intercourse after a laparoscopic hysterectomy three months ago. Approximately one hour after intercourse, her husband was using a running vibrator on her and lost his grip and it went inside. She was in distress. A mechanical buzzing could be audibly heard as well as palpated throughout the abdomen.

Our patient presented with a vaginal cuff dehiscence complicated by a small bowel evisceration through the vagina with an intraabdominal foreign body (the vibrator) in the peritoneal cavity (Fig. 1). An exploratory laparotomy was performed to retrieve the vibrator, repack the bowel, and repair the vaginal cuff.

A vaginal cuff dehiscence is the separation of the anterior and posterior edges of the vaginal cuff. ${ }^{1}$ This can be life threatening if the bowel eviscerates through the introitus and results in intestinal ischemia and infection.' Patients commonly present with pelvic or abdominal pain, bleeding, or watery discharge. ${ }^{2}$ Evisceration of the bowel occurs in $70 \%$ of vaginal dehiscences. ${ }^{2} \mathrm{Di}-$ rect trauma from sexual intercourse is the most common etiology for cuff dehiscence. ${ }^{3}$ Other etiologies include: age, chronic steroid use, diabetes, foreign objects, hypothyroidism, poor surgical technique, and the Valsalva maneuver..$^{1-4}$ The median time to dehiscence averages 1.5 to 3.5 months postoperatively. ${ }^{3}$ Half of the dehiscences occurred after a robotic or laparoscopic hysterectomy. ${ }^{2}$ Techniques that use different suturing methods, electrocautery, and a magnified visual field may factor into the high dehiscence rates seen after a robotic or laparoscopic hysterectomy. ${ }^{2}$

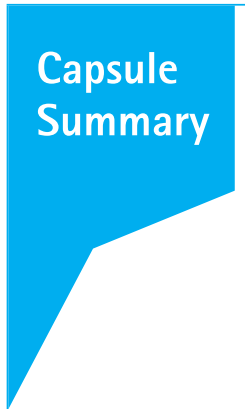

What is already known

Vaginal cuff dehiscence after a hysterectomy is relatively common.

What is new in the current study

A patient should receive a follow-up pelvic examination after a hysterectomy and before resuming sexual activity to ensure the vaginal cuff has healed and is not open.
elSSN: 2383-4625

Received: 21 July 2016

Revised: 15 August 2016

Accepted: 15 August 2016

Correspondence to: Eric F. Reichman Emergency Department, University of Texas Health Science Center at Houston-Medical School, 3907 Fielder Circle, Missouri City, TX 77459-6654, USA

E-mail: Eric.F.Reichman@gmail.com

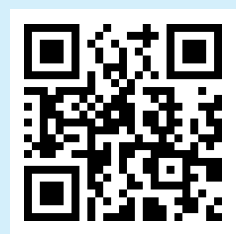

How to cite this article:

Reichman EF. Intraabdominal vibrator due to a vaginal cuff dehiscence. Clin Exp Emerg Med 2016;3(4):262-263.

This is an Open Access article distributed under the terms of the Creative Commons Attribution Non-Commercial License (http:// creativecommons.org/licenses/by-nc/3.0/). 


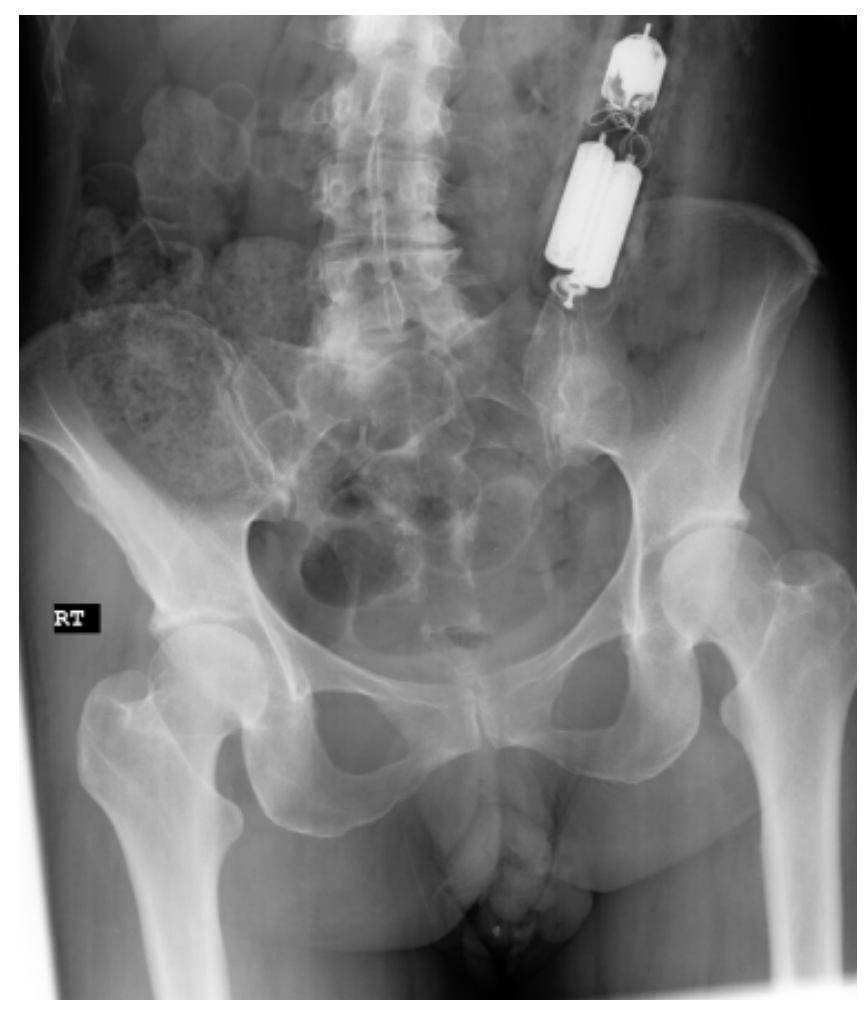

Fig. 1. Plain radiograph of the abdomen showing the location of the intraabdominal vibrator. The bowel can be seen eviscerating through the introitus. $\mathrm{RT}$, right side.

\section{CONFLICT OF INTEREST}

No potential conflict of interest relevant to this article was reported.

\section{REFERENCES}

1. Koo YJ, Kim DY, Kim JH, Kim YM, Kim YT, Nam JH. Vaginal cuff dehiscence after hysterectomy. Int J Gynecol Obstet 2013;122: 248-52.

2. Cronin B, Sung VW, Matteson KA. Vaginal cuff dehiscence: risk factors and management. Am J Obstet Gynecol 2012;206: 284-8.

3. Clarke-Pearson DL, Geller EJ. Complications of hysterectomy. Obstet Gynecol 2013;121:654-73.

4. Ceccaroni M, Berretta R, Malzoni M, et al. Vaginal cuff dehiscence after hysterectomy: a multicenter retrospective study. Eur J Obstet Gynecol Reprod Biol 2011;158:308-13. 